\title{
CURRENT STATUS OF MALARIA AND ANTI-MALARIAL DRUG RESISTANCE IN SRI LANKA
}

\author{
Rupika S. Rajakaruna ${ }^{1}$, Priyanie H. Amerasinghe ${ }^{2}$, Gawrie N.L. Galappaththy ${ }^{3}$, Flemming \\ Konradsen $^{4}$, Olivier J.T. Briet ${ }^{5}$ and Michael Alifrangis ${ }^{4}$ \\ ${ }^{1}$ Department of Zoology, University of Peradeniya, Peradeniya, Sri Lanka. \\ ${ }^{2}$ IWMI, C/O ICRISAT, Patancheru - 502 324, Hyderabad, Andhra Pradesh, India. \\ ${ }^{3}$ Anti-Malarial Campaign Head Office, Colombo, Sri Lanka. \\ ${ }^{4}$ Centre for Medical Parasitology, Institute of International Health, Immunology and Microbiology, \\ University of Copenhagen, Copenhagen, Denmark. \\ ${ }^{5}$ International Water Management Institute (IWMI), P.O. Box 2075, Colombo, Sri Lanka. \\ Accepted 12 May 2008
}

\begin{abstract}
Even though malaria continues to cause high morbidity and mortality in most of the malaria endemic countries in the world, it is currently not a major health problem in Sri Lanka. Despite the low malaria incidence, the development and spread of anti-malarial drug resistance, combined with a recent increase in the armed conflict hindering provision of effective health services will make it difficult to control malaria in Sri Lanka. Since chloroquine (CQ) resistant Plasmodium falciparum was first reported from Dambulla area in 1984, the number has increased to more than 50\% observed in vivo from various endemic areas. In concordance with this, single nucleotide polymorphisms (SNPs) in genes of $P$. falciparum responsible for CQ resistance are present. A limited number of trials have investigated the efficacy of the second line drug, sulfadoxine/ pyrimethamine (SP) against $P$. falciparum and a few cases of resistance have been reported. Moreover, SNPs in $P$. falciparum genes responsible for SP resistance are present and may constitute a sign of evolving SP resistance development. For P. vivax, drug resistance is not yet recorded as a problem in Sri Lanka, however the prevalence of SP resistant SNPs in $P$. vivax populations seems high and may pose a risk despite that SP is not used directly against $P$. vivax infections. Continuous monitoring of drug efficacy in vivo, as well by measuring the prevalence of SNPs related to drug resistance are major issues to be addressed.
\end{abstract}

\section{INTRODUCTION}

Malaria is a major public health problem deeply rooted in poor communities, impeding the economic growth and development of the malaria endemic countries in the world. The situation varies from country to country depending on malaria epidemiology and the effectiveness of control programmes where one of the key strategies has been the promotion of early diagnosis and treatment with effective antimalarials (WHO 2001).

As identified by the World Health Organization (WHO), the South-East Asian countries with endemic malaria are Bangladesh, Bhutan, India, DPR Korea, India, Indonesia, Maldives, Myanmar, Nepal, Sri Lanka, Thailand, and Timor-Leste. However, Maldives has had no reported malaria cases since 1984 . These 10 endemic countries appear to contribute with 30\% of the morbidity and $8 \%$ mortality to the overall malaria burden in the world.

According to WHO reports (2007), during 2000-2005 malaria incidences have shown a dramatic downward trend in the South-East Asia Region. On a regional level there is a slight increase in reported cases during 2005, but the same decreased at a country level for DPR Korea, Sri Lanka, Bhutan, Bangladesh, India and Myanmar. While frequent epidemics are being observed in many countries in the region, Bhutan, Bangladesh, Sri Lanka and Nepal have not reported any recent major epidemics since 2000. Key control strategies in all these countries have been vector control by indoor residual spraying, installment of insecticide treated nets and prompt

*Corresponding author’s email: rupika.r@gmail.com 
treatment of malaria-confirmed cases, as well as enhancement of malaria surveillance and epidemic preparedness (WHO 2007). Although regionally a downward trend in malaria cases is being observed, falciparum malaria cases appear to have increased slightly (http:/www.searo.who.int /LinkFiles/Malaria_in_the_SEAR_Trends_Malara 1977_2004). However, the strategy has been compromised due to the widespread development of resistance to anti-malarial drugs, especially observed for the most severe malaria species, Plasmodium falciparum.

\section{Current malaria situation in Sri Lanka}

In Sri Lanka, malaria is caused by either $P$. falciparum or $P$. vivax infections, where the majority of reported cases $(65 \%-80 \%)$, is due to $P$. vivax (Konradsen, 2000 and references therein). During the 1990s, 200,000 to 400,000 laboratoryconfirmed malaria cases were reported annually in Sri Lanka. However, the numbers decreased dramatically from 2000 to 2007 (Figure 1). The total number of malaria cases for both $P$. falciparum and P. vivax in 2007 was only 196 and 591 in 2006 (Annual Report of the AMC, 2007). The estimated population at risk has decreased to 5 million in the year 2006, from an estimated 12 million in the late 1990s (Department of Census and Statistics - Sri Lanka, 2007). Figure 2 shows the number of microscopically confirmed malaria patients reported at district wise for year 2007. The highest number of the cases was reported from Trincomalee district. Considering the low island-wide incidence, malaria cannot be considered a major public health problem currently in Sri Lanka. Briet et al.,, (2005) attributed the decrease in the overall malaria incidences in the country since 2000 to the reduced incidences in the districts in the conflict affected areas, especially Vavuniya and Kilinochchi. The reduction in the overall malaria incidence in the country is attributed to the reudction in cases in the districts of Vavuniya and Kilinochchi, where the antimalaria campaign was able to closely monitor and contain outbreaks in a timely manner, with the establishment of the peace process in the North of the country (Briet et al., 2005). Mobile clinics, active case detections and prompt treatment of cases were largely responsible for bringing down the case loads in these districts.

In 2004, when tsunami hit the island, concerns were raised that vector borne diseases may increase with the excessive flooding of areas. However, the likelihood of a post-tsunami malaria outbreak was considered to be low, giving the fact that the principal vector, Anopheles culicifaces does not thrive under salt water conditions (Villholth et al., 2005 and Briet et al., 2005). Accordingly, the malaria incidences for 2005 was even lower than for 2004 in most of the districts including the tsunami affected areas. It is possible that the actual incidences in the tsunami affected areas may have been higher than recorded, because of the prevailing conditions and displacement of people, however the overall incidence was not affected significantly, thus the tsunami did not negatively influence the malaria situation in Sri Lanka (Briet et al., 2006). While the country is experiencing low levels of incidence the current escalating armed conflict may pose a new problem in to malaria control. Also the recent findings on drug resistance show a developing trend that should not be ignored.

\section{Anti-malarial drug resistance}

Chloroquine (CQ) soon after introduced in the 1950's quickly became the main drug of choice globally to treat uncomplicated $P$. falciparum infections for instance as part of the Global Malaria Eradication campaign, launched by the WHO in 1955. However, P. falciparum did eventually develop resistance to $\mathrm{CQ}$, and has spread to almost all the endemic countries today (Wellems and Plowe, 2001; Price and Nosten, 2001). Thus, CQ has almost exclusively been replaced by alternative drugs like sulfadoxine/ pyrimethamine (SP, commercially known as Fansidar ${ }^{\circledR}$ ) and amodiaquine, for both of which high level of resistance has been recorded from several malaria endemic countries. The latest strategy is an almost global introduction of the artemisinin combination treatments (ACTs) against $P$. falciparum, proven to be highly efficacious and so far without showing signs of resistance in vivo. However, in vitro studies have indicated otherwise (Jambou, 2005).

\section{Surveillance of drug resistance}

The efficacy of anti-malarial drugs is assessed by performing routine in vivo efficacy trials as well as in vitro drug susceptibility tests on parasite populations according to WHO guidelines and providing warning of rising drug resistance in vivo (Shretta et al., 2000; Brockman et al., 2000; WHO 2001). 


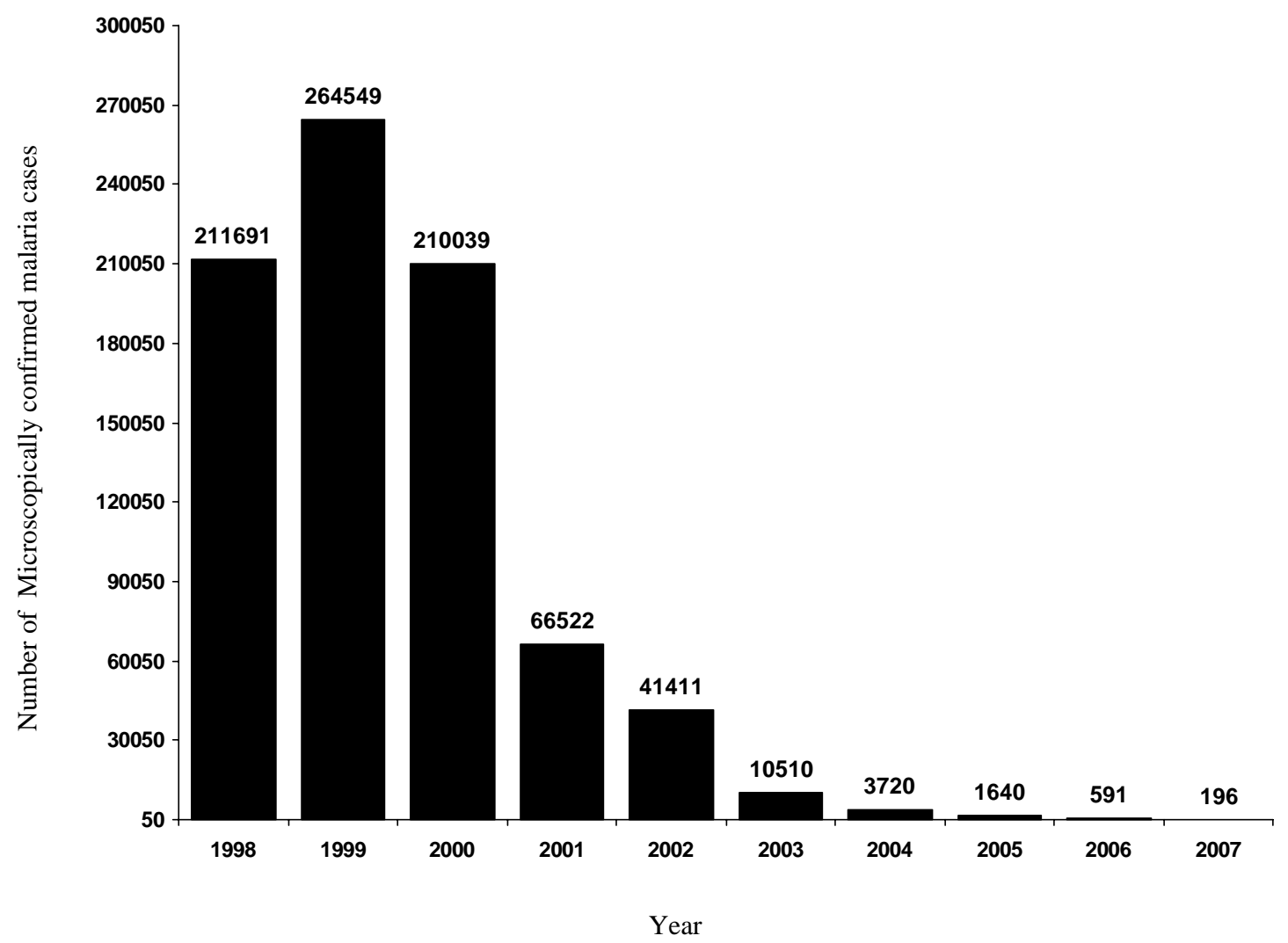

Figure 1. The number of microscopically confirmed malaria cases from 1998 to 2007 in Sri Lanka.

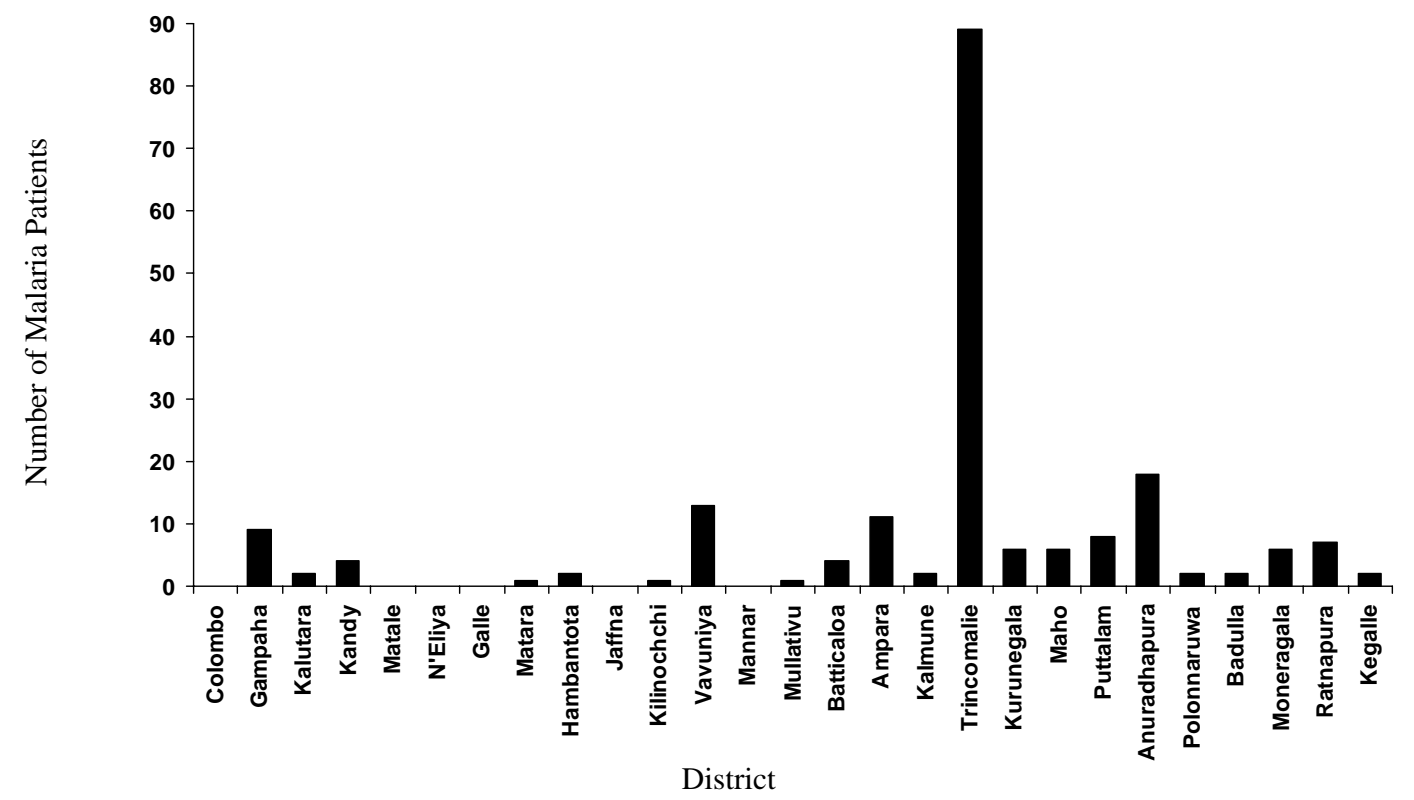

Figure 2. District -wise microscopically confirmed malaria patients in Sri Lanka for year 2007. 
Alternatively, molecular markers of $P$. falciparum resistance to $C Q$ and $P$. falciparum $/ P$. vivax resistance to $\mathrm{SP}$ have been identified and surveillance of these markers can provide additional information to in vivo trials and may act as early warning of evolving resistance in the parasite population (Djimde et al., 2001a; 2001b; Kublin et al., 2002).

In brief, the development of CQ resistance is due to a single nucleotide polymorphism (SNP) at position T76 of the $P$. falciparum CQ resistance transporter ( $P f c r t)$ gene (Fidock et al., 2000), while a multidrug resistance analogue (Pfmdr1) Y86 variation may modulate its degree of resistance (Sanchez and Lanzer, 2000). Resistance of $P$. falciparum to SP is due to SNPs in the dihydrofolate reductase (Pfdhfr) and the dihydropteroate synthetase (Pfdhps) genes (Omar et al.,, 2001; Kublin et al., 2002; Kyabayinze et al., 2003). In Pfdhfr, mutations at codons 51 (N51I), 59 (C59R), 108 (S108N) and 164 (I164L) have shown to confer resistance to pyrimethamine (Cowman et al., 1988; Peterson et al., 1988; Plowe, 2005). Mutation at codon 108 is usually observed first and carrying additional mutations at codons 51, 59 and 164 results in double, triple or quadruple mutants and are increasingly resistant to pyrimethamine. Regarding sulfadoxine resistance in $P$. falciparum mainly mutations at codon 437 and codon 540 of Pfdhps provide resistance (Kublin et al., 2002).

In $P$. vivax, pyrimethamine resistance has been shown to involve several SNPs, but mainly associated with mutations at codons 58 (S58R) and 117 (S117N or S117T) with additional mutations at codons 57 (F57L) and 61 (T61M) in the Pvdhfr gene (Eldin et al., 1998; Kublin et al.,, 2002; Imwong et al., 2003; Hastings et al., 2004; Hastings et al., 2005). The quadruple mutant haplotype $(57 \mathrm{~L}+58 \mathrm{R}+61 \mathrm{M}+117 \mathrm{~T})$ increases $P$. vivax resistance to pyrimethamine by more than 500 times (Hastings et al., 2004; Hastings et al., 2005). Sulfadoxine resistance in $P$. vivax is caused by SNPs in the Pvdhps gene (Hastings et al.,2004; Hastings et al., 2005). It has been claimed that $P$. vivax possess some level of innate sulfadoxine tolerance and the wildtype at codon 585 (V585) may be the cause of the resistance (Korsinczky et al., 2004) while additional mutations at codons 383 (A383G) and 553 (A553G) in Pvdhps most likely increases resistance levels (Korsinczky et al., 2004). Due to the assumption that $P$. vivax is innate resistant to SP, SP is not used deliberately against $P$. vivax infections in countries with endemic $P$. vivax such as Sri Lanka. However, much to the surprise of researchers and clinicians Leslie et al., (2007) have recently shown that SP is in fact highly effective against $P$. vivax infections in vivo.

\section{Anti-malarial drug resistance in Sri Lanka}

In Sri Lanka, the first line drug recommended for treatment of $P$. vivax and $P$. falciparum (until May 2008) malaria cases is a combination of CQ and primaquine (PQ). The recommended treatment for $P$. falciparum malaria has been changed since May 2008 to ACT. After two decades of extensive use, resistance to CQ for falciparum malaria was first reported in 1984 from the Dambulla area in the Matale District (Ratnapala et al., 1984). Dambulla was exposed to almost uninterrupted malaria transmission throughout 1984 experiencing two focal outbreaks of $P$. falciparum malaria and the population had been subjected to mass CQ administration regimes during this period. Ratnapala et al., (1984) suggest that the emergence of resistance to CQ may have resulted from individuals being subjected to subtherapeutic doses of the drug or due to introduction of resistant strains to the region via frequent visits of gem traders from Thailand to the gem-mining areas in Dambulla. Several years later Handunetti et al., (1996) reported in vivo CQ resistance in patients from a malaria endemic area (Kataragama) and non-endemic area (Colombo) where the resistance levels were 30\% and 55\%, respectively. The results of in vivo tests carried out in 1999 (21-days observation) in high $P$. falciparum prevalent districts (except the North-East Province) revealed that approximately $50 \%$ of the cases was infected with CQ resistant $P$. falciparum (Galappaththy, 2003). Another in vivo study showed that $54 \%$ of $P$. falciparum infections among security forces personnel in Mannar District in the Northern Province of Sri Lanka were resistant to CQ (Hapuarachchi et al., 2004). To our knowledge, molecular markers of $P$. falciparum CQ resistance has not been studied in Sri Lanka. However, preliminary results on 19 samples collected from six malaria endemic districts of Sri Lanka in 2005 showed an exclusive prevalence of the mutant type of the Pfcrt gene (unpublished results).

$\mathrm{SP}$ is the second line of drug given to treat $\mathrm{CQ}$ resistant falciparum malaria in Sri Lanka before introduction of ACT in 2008. SP is administered only by government hospitals as an out-patient treatment. The first $P$. falciparum SP resistant case was reported in 1992 from a resident in Colombo, which is a malaria non-endemic area, 
however, the patient during the previous months had visited Chilaw, a malaria endemic area of Sri Lanka, but had also traveled in the Asian region making it difficult to assess if the case was imported or truly endemic (Handunetti et al.,1994). Since this first report, only a few cases of clinical failure with SP have been reported (Sarukkali and De Silva, 1994; Gunasekara and Perera, 1996). One of these cases was reported from Chilaw and repeated treatment failure with CQ and SP lead to the administration of quinine (Gunasekara and Perera, 1996). Quinine, the third line of drug, is recommended for SP resistant cases as an in-patient treatment at government hospitals.

A recent study on SP resistance of $P$. falciparum in the Mannar district (Northern Province) in 2002, revealed that $85 \%$ of the patients had mutant alleles at c108 (S108N) as well as at c59 (C59R) of the Pfdhfr. However, none of the patients showed any clinical or parasitologic evidence of resistance to SP, possibly due to lack of mutations at c51 of Pfdhfr as well as few mutations in Pfdhps (Hapuarachchi et al., 2006).

Since the first CQ resistant $P$. vivax infection was identified in Papua New Guinea in 1989 (Rieckmann et al., 1989), resistant cases have been recorded from various other countries. Resistance to SP in P. vivax has been observed sporadically (Pukrittayakamee et al., 2004) but this has not been assessed in vivo in many countries including Sri Lanka since SP is not used against vivax malaria. Surprisingly, a recent study carried out in Sri Lanka reported high prevalence (31\%) and diverse distribution of SNPs in the genes $d h f r / d h p s$ of $P$. vivax (conferring resistance to SP) across the island despite that SP is not used against $P$. vivax (Schousboe et al., 2007). This frequency of mutant haplotypes was significantly higher in the Northern region and this may be indirectly caused by the armed conflict in the region. Furthermore, a certain $P v d h f r$ haplotype was only observed in the northern districts and it was speculated that the frequent visits of people to south India from the northern parts of Sri Lanka may been have introduced this particular haplotype from Chennai where it was highly prevalent (Kaur et al., 2006).

Thus, In vivo drug resistance on Sri Lanka is relatively restricted to $P$. falciparum and absent in $P$. vivax, but the prevalence of resistance alleles seems to be high (Hapuarachchi et al., 2006; Schousboe et al., 2007) and may be an early warning of evolving resistance in the parasite populations. However, large-scale epidemiological studies of drug resistance, both in vivo and at molecular level are lacking and the situation in the country is thus incompletely assessed.

\section{Preserving the efficacy of antimalarial drugs}

Preserving the efficacy of the anti-malarial drugs in use is of critical importance to public health in malaria endemic areas. Widespread use of antimalarial drugs for all types of fever and exposure to sub-therapeutic doses of drugs due to non-compliance of recommended dosages contribute markedly to drug resistance and necessitate continual change in malaria treatment guidelines. In support of this the WHO (1993) has recognized that monitoring and influencing the quality of private services are key components of effective malaria treatment. The involvement of private drug vendors in malaria treatment is particularly high in developing countries, but maintaining the quality of their service and monitoring compliance with national malaria treatment guidelines is difficult (WHO 1993). A recent study carried out in seven malaria endemic districts of the island showed that private drug vendors lack awareness of the overall malaria treatment guidelines of Sri Lanka. However, they sell almost exclusively the government established first line anti-malarial drugs and other anti-malarials are rarely found in private outlets (Rajakaruna et al., 2006). With dwindling malaria cases in the country, the demand for antimalarials has been low. This shows that people's knowledge on antimalarial drugs and the awareness among the drug vendors on government drug policies, may be due to the decline in sales.

\section{CONCLUSION}

Considering the resurgence of malaria in 1968 after the Global Malaria Eradication Program failed, malaria in Sri Lanka has the potential for causing epidemics. Asymptomatic infections of $P$. falciparum and $P$. vivax and dormant stages of $P$. vivax normally provide the parasite reservoir for bridging periods of low seasonal transmission. Under the present policy of administering primaquine (PQ) in addition to chloroquine in treatment of uncomplicated cases, the reservoir of the dormant stages of $P$. vivax will be low and this will delay a possible outbreak. Major issues to be addressed in the ongoing control efforts relate to the monitoring of the prevalence of drug resistant parasites and hidden parasite reservoirs at the earliest stage. A national surveillance 
programme providing comprehensive data is a valuable source to adjust policy and management procedures.

\section{REFERENCES}

Briet, O.J.T., Galappaththy, G.N.L., Amerasinghe, P.H. and Konradsen, F. (2006) Malaria in Sri Lanka: one year post-tsunami. Malaria Journal. 5: 42.

Briet, O.J.T., Galappaththy, G.N.L., Konradsen, F., Amerasinghe, P.H. and Amerasinghe, F.P. (2005) Maps of Sri Lanka malaria situation preceding the tsunami and key aspects to be considered in the emergency phase and beyond. Malaria Journal. 4: 8.

Brockman, A., Price, R.N., van Vugt, M., Heppner, D.G., Walsh, D., Sookto, P., Wimonwattrawatee, T. Looareesuwan, S., White, N.J., and Nosten, F. (2000) Plasmodium falciparum antimalarial drug susceptibility on the north-western boarder of Thailand during the five years of extensive use of artesunate-mefloquine. Transactions of Royal Society of Tropical Medicine and Hygiene. 94: 537-544.

Cowman, A.F., Morry, M.J., Biggs, B.A., Cross, G.A. and Foote, S.J. (1988) Amino acid changes linked to pyrimethamine resistance in the dihydrofolate reductase-thymidylate reductase synthase gene of Plasmodium falciparum. Proceedings of the National Academy of Science, USA. 85: 9109-9113.

Department of Census and Statistics - Sri Lanka (2007) Estimated Mid-year Population by Sex and District

http://www.statistics.gov.lk/PopHouSat/PDF/p20 \%20Mid-Year\%20estimates.pdf

http://www.statistics.gov.lk/PopHouSat/PDF/p20 \%20Mid-Year\%20estimates.pdf

Djimde, A., Doumbo, O.K., Cortese, J.F., Kayentao, K., Doumbo, S., Diourte, Y., Dicko, A., Su, X.Z., Nomura, T., Fidock, D.A., Wellems, T.E., Plowe, C.V. (2001a) New England Journal of Medicine 344: 257-263.

Djimde, A., Doumbo, O.K., Steketee, R.W., Plowe, C.V. (2001b) Application of a molecular marker for surveillance of chloroquine-resistant falciparum malaria. Lancet 358: 890-891.

Eldin, D.P., Basco, L.K., Tahar, R., Ouatas, T., and Mazabraud, A. (1998) Analysis of the
Plasmodium vivax dihydrofolate reductasethymidylate synthase gene sequence. Gene 211:177-85.

Fidock, D.A., Nomura, T., Talley, A.K., Cooper, R.A., Dzekunov, S.M., Ferdig, M.T., Ursos, L.M., Sidhu, A.B., Naude, B., Deitsch, K.W., Su, X.Z., Wootton, J.C., Roepe, P.D. and Wellems, T.E. (2000) Mutations in the $P$. falciparum digestive vacuole transmembrane protein PfCRT and evidence for their role in chloroquine resistance. Molecular Cell 6: 861-871

Galappaththy, G.N.L. (2003) A study of Chloroquine resistant $P$. falciparum_malaria in Sri Lanka. MD thesis. Postgraduate Institute of Medicine, University of Colombo.

Gunasekara, D.P.S. and Perera, D.P.E.R. (1996) Multidrug resistant malaria in Sri Lanka. Ceylon Medical Journal. 41:170-171.

Handunnetti, S.M., Gunewardena, D.M., Pathirana, P.P., Ekanayake, K., Weerasinghe, S., and Mendis, K.N. (1996) Features of recrudescent chloroquine-resistant $P$. falciparum infections confer a survival advantage on parasites and have implications for disease control. Transactions of Royal Society of Tropical Medicine and Hygiene 90: 563-567.

Handunnetti, S.M., Jayasinghe, S., Pathirana, P.P., Fernando, R., Sheriff, M.H., Mendis, K.N. (1994) Sulphadoxine-pyrimethamine and chloroquine resistant $P$. falciparum infection in Sri Lanka. Ceylon Medical Journal 39: 45-46.

Hapuarachchi, H.A.C., Dayanath, M.Y.C., Abeysundera, S., Bandara, K.B.A.T., Abeyewickreme, W., and de Silva, N.R. (2004) Choloquine resistant falciparum malaria among security forces personnel in the Northern Province of Sri Lanka. Ceylon Medical Journal 49: 47-51.

Hapuarachchi, H.A.C., Dayanath, M.Y.C., Bandara, K.B.A.T., Abeysundera, S., Abeyewickreme, W., de Silva, N.R., Hunt, S.Y. and Sibley, C.H. (2006) Point mutations in the dihydrofolate reductase and dihydrofolate systhase genes of Plasmodium falciparum and resistance to sulfadoxine-pyrimethamine in Sri Lanka. American Journal of Tropical Medicine and Hygiene 74(2): 198-204.

Hastings, M.D., Maguire, J.D., Bangs, M.J.Zimmerman, P.A., Reeder, J.C., Baird, J.K., and Sibley, C.H. (2005) Novel Plasmodium vivax 
dhfr alleles from the Indonesian Archipelago and Papua New Guinea: association with pyrimethamine resistance determined by a Saccharomyces cerevisiae expression system. Antimicrobial Agents and Chemotherapy 49:73340.

Hastings, M.D., Porter, K.M., Maguire, J.D. Susanti, I., Kania, W., Bangs, M.J., Hopkins, S.C. and Baird, J.K. (2004) Dihydrofolate Reductase Mutations in Plasmodium vivax from Indonesia and Therapeutic Response to Sulfadoxine Plus Pyrimethamine. Journal of Infectious Diseases 189:744-50.

Imwong, M., Pukrittayakamee, S., Renia, L., Letourneur, F., Charlieu, J.P., Leartasakulpanich, U., Looareesuwan, S., White, N.J., and Snounou, G. (2003) Novel point mutations in the dihydrofolate reductase gene of Plasmodium vivax: evidence for sequential selection by drug pressure. Antimicrobial Agents and Chemotherapy 47:1514-1521.

Jambou, R., Legrand, E., Niang, M., Khim, N., Lim, P., Volney, B., Ekala, M.T., Bouchier, C., Esterre, P., Fandeur, T., Mercereau-Puijalon, O.S (2005). Resistance of Plasmodium falciparum field isolates to in-vitro artemether and point mutations of the SERCA-type PfATPase6. Lancet 366:1960-1963.

Kaur, S., Prajapati, S.K., Kalyanaraman, K., Mohmmed, A., Joshi, H., and Chauhan, V.S. (2006) Plasmodium vivax dihydrofolate reductase point mutations from the Indian Subcontinent. Acta Tropica. 97:174-180.

Konradsen, F., Amerasinghe, F.P., van der Hoek, W. and Amarasinghe, P.H. (2000) Malaria in Sri Lanka: Current knowledge on transmission and control. Colombo, Sri Lanka. International Water Management Institute. Pp.45-58.

Korsinczky M, Fischer K, Chen N, Baker J, Rieckmann K, and Cheng Q. (2004) Sulfadoxine resistance in Plasmodium vivax is associated with a specific amino acid in dihydropteroate synthase at the putative sulfadoxine-binding site. Antimicrobial Agents and Chemotherapy 48: 2214-22.

Kublin, J.G., Dzinjalamala, F.K., Kamwendo, D.D., Malkin, E.M., Cortese, J.F., Martino, L.M., Mukadam, R.A., Rogerson, S.J., Lescano, A.G., Molyneux, M.E., Winstanley, P.A., Chimpeni, P., Taylor, T.E., and Plowe, C.E. (2002) Molecular markers for failure of sulfadoxine-pyrimethamine and chlorproguanil-dapsone treatment of Plasmodium falciparum malaria. Journal of Infectious Diseases 185: 380-8.

Kyabayinze, D., Cattamanchi, A., Kamya, M.R., Rosenthal, P.J. and Dorsey, G. (2003) Validation of a simplified method for using molecular marker to predict sulphadoxine-pyrimethamine treatment failure in African children with falciparum malaria. American Journal of Tropical Medicine and Hygiene. 69: 247-252.

Leslie, T., Mayan, M.I., Hasan, M.A., Safi, M.H., Klinkenberg, E., Whitty, C.J., Rowland, M. (2007) Sulfadoxine-pyrimethamine, chlorprogua nil-dapsone, or chloroquine for the treatment of Plasmodium vivax malaria in Afghanistan and Pakistan: a randomized controlled trial. Journal of American Medical Association 297: 22012209.

Omar, S.A., Adagu, I.S. and Warhurst, D.C. (2001) Can Pre-treatment screening for dhps and dhfr point mutations in Plasmodium falciparum infections be used to predict sulphadoxinepyrimethamine treatment failure? Transactions of Royal Society of Tropical Medicine and Hygiene 95: 315-319.

Peterson, D.S., Walliker, D. and Wellems, T.E. (1988) Evidence that a point mutation in dihydrofolate reductase thymidylate synthase confers resistance to pyrimethamine in falciparum malaria. Proceedings of the National Academy of science USA. 85: 9114-9118.

Plowe, C.V. (2005) Antimalarial drug resistance in Africa: strategies for monitoring and deterrence. Current topics in Microbiology and Immunology 295: 55-79.

Price, R.N. and Nosten, F. (2001) Drug resistant falciparum malaria: clinical consequences and strategies for prevention. Drug Resistance Update. 4:187-196.

Pukrittayakamee, S., Imwong, M., Looareesuwan, S. and White, N.J. (2004) Therapeutic responses to antimalarial and antibacterial drugs in vivax malaria. Acta Tropica. 89: 351-356.

Rajakaruna, R.S., Weerasinghe, M., Alifrangis, M., Amerasinghe, P.H. and Konradsen, F. (2006) Role of private drug vendors in malaria treatment in Sri Lanka. Journal of Vector Borne Diseases 43:58-65. 
Ratnapala, R., Subramaniam, K., Yapabandara, M.G., and Fernando, W.P. (1984) Chloroquine resistant $P$. falciparum in Sri Lanka. Ceylon Medical Journal 29: 135-145.

Rieckmann, H., Davis, D.R. and Hutton, D.C. (1989) Plasmodium vivax resistance to chloroquine? Lancet 2: 1183-1184.

Sanchez, C. and Lanzer, M. (2000) Changing ideas on chloroquine in Plasmodium falciparum. Current Opinion on Infectious Diseases 13: 653658.

Sarukkali, C. and De Silva, S.G. (1994) Falciparum malaria resistant to sulphadoxinepyrimethamine and associated with eosinophilia. Ceylon Journal of Child Health 23: 18-20.

Schousboe, M.L., Rajakaruna, R.S., Salanti' A., Hapuarachchi, H.C. Galappaththy, G.N.L., Bygbjerg, I.C., Amerasinghe, P.H., Konradsen, F. and Alifrangis, M. (2007) Island-wide differences in single nucleotide polymorphisms of the $P$. vivax dihydrofolate reductase (Pvdhfr) and dihydropteroate synthetase ( $P v d h p s)$ genes in Sri Lanka. Malaria Journal 6: 28.

Shretta, R., Omumbo, J., Rapuoda, B. and Snow, R.W. (2000) Using evidence to change antimalarial drug policy in Kenya. Tropical Medicine and International Health 5: 755-764.

Sibley, C.H., and Ringwald, P. (2006) A database of antimalarial drug resistance. Malaria Journal 5: 48-56.
Villholth, K.G., Amerasinghe, P.H., Jeyakumar, P., Panabokke, C.R., Wolley, O., Weerasinghe, M.D., Amalraj, N., Prathepaan, S., Burgi, N., Lionelrathne, D.M.D.S., Indrajith, N.G. and Pathirana, S.K.R. (2005) Tsunami impacts on shallow ground water and associated water supply on the east coast of Sri Lanka. a posttsunami well recovery support initiative and an assessment of groundwater salinity in three areas of Batticaloa and Ampara district in eastern Sri Lanka. International Water Management Institute Pp. 68. http://www.iwmi.org

Wellems, T.E. and Plowe, C.V. (2001) Chloroquine-resistant malaria. Journal of Infectious Diseases 184: 770-776.

World Health Organization Implementation of the Global Malaria Control Strategy: Report of a WHO study group on Implementation of the Global Plan of Action for Malaria Control (1993-2000). WHO Technical Report, 839:1-35. World Health Organization, Geneva.

World Health Organization (2001) The use of antimalatial drugs. Report of a WHO informal consultation. Report WHO/CDS/RBM/2001.33 WHO. Geneva, Switzerland.

World Health Organization (2007) Malaria Disease Burden in SEA Region. WHO. Geneva, Switzerland www.searo.who.int/EN/Section10/ Section21/Section340-4018.htm 